\title{
SURREALISMO E PSICANÁLISE: EM QUE REAL SE ENTRA?
}

\author{
LuCia CASTELlo BRANCO
}

Universidade Federal de Minas Gerais

\begin{abstract}
Resumo a escrita, a letra, o traço, o real.

Palavras-chave

Literatura; psicanálise; surrealismo; real.
\end{abstract}

O texto desenvolve uma discussão sobre os limites entre a literatura e a psicanálise, a partir da noção de "real" que esses dois campos encerram. Propõe-se que o surrealismo e a psicanálise se tangenciam em alguns pontos assinalados pelo privilégio dado a algumas categorias, como

Abstract

This paper develops a discussion of the limits between literature and psychoanalysis, departing from the notion of real which both fields encompass. It proposes that surrealism and psychoanalysis touch in points signaled by the privilege granted to categories such as writing, letter, trace, real.

Keywords

Literature; psychoanalysis; surrealism; real.

1928. As imagens cortadas do cinema mudo em preto-e-branco reproduzem cenas de corte. $\mathrm{O}$ espectador, em princípio, é lançado à cena de um olho de mulher cortado pela lâmina da navalha. Essa cena, brutalmente real, é de repente transformada no lírico clichê cinematográfico de uma lua atravessada pela nuvem. Até que um homem sobre a bicicleta corte a paisagem. Ou que o olhar da mulher que folheia o livro (nele estampa-se uma figura de Vermeer - La dentellière - em que se mostra uma mulher tecendo a renda) seja atravessado pela bicicleta do homem que atravessa a paisagem. Mas há ainda a mão cortada e lançada sobre o asfalto, as páginas cortadas do livro, a borboleta recortada sobre a superfície do chão. Até que tudo finalize com a mulher e o homem à beira-mar, recolhendo panos recortados como restos de sargaços. Até que tudo finalize com a mulher e o homem enfiados na areia como duas figuras de mulher e homem recortadas de uma folha de papel. E o que resta é a imagem de um cão - mais nome que figura - como um recorte do texto fílmico, letra incógnita de sua escritura: Le chien andalou.

1928. Le chien andalou. Filme realizado por Dalí e Buñuel. Mudo, o filme realiza plasticamente, pelo seu caráter pictural, sua dimensão de letra, aquilo que realizaria por meio da voz: "Da mesma forma que o som penetra o ouvido e o espírito, o ato pictográfico atinge e bombardeia, perfura, percute e faz entrar, atravessa". ${ }^{288}$

\footnotetext{
${ }^{288}$ Jacques Derrida, Enlouquecer o subjétil, São Paulo, Unesp, 1998, p. 55.
} 
1928. Le chien andalou, uma obra surrealista. O que importa aos surrealistas é, segundo Jaqueline Chénieux-Gendron, captar "o impulso motor para produzir grafos ou letras e conduzir quer ao desenho, quer à escrita". ${ }^{289}$

Le chien andalou: grafo ou letra? Desenho ou filme? Escrita automática?

"Não há literatura. Quando se escreve só importa saber em que real se entra, e se há técnica adequada para abrir caminho a outros", ${ }^{290}$ assim dizia Maria Gabriela Llansol, em 1981. Antes de Llansol, foi preciso que a psicanálise e o surrealismo surgissem para instaurar, na radicalidade de seus gestos, outras noções de real. Por isso, talvez afirmativas como essa da autora não nos causem, hoje, tanto desconforto. Porque sabemos que onde repousava uma noção já cristalizada da arte e da literatura como formas de representação situa-se, hoje, a noção de escritura. E a ela já não corresponde um olhar guiado por uma tendência à leitura hermenêutica, mas, na melhor das hipóteses, pela busca de uma certa legibilidade, mesmo que os textos e as imagens já não sejam dados a ler.

Mas se a psicanálise e o surrealismo podem ser situados num mesmo contexto histórico no qual o que se observa, no campo das artes, pode ser entendido, superficialmente, como o início do que hoje chamamos de "crise da representação", isso não quer dizer que ambos - a psicanálise e o surrealismo - compartilhem exatamente os mesmos conceitos, ou possuam as mesmas fundamentações teóricas.

É verdade que a descoberta do inconsciente foi de fundamental importância para a concepção dos movimentos de vanguarda, sobretudo para o surrealismo, que, já no manifesto de 1924, de Breton, situa os pilares dessa nova arte nas dimensões do inconsciente, do sonho e, especialmente, do desejo.

Sabe-se que os surrealistas chegaram mesmo a supervalorizar (de maneira um tanto carnavalizada, é verdade) as figuras do louco e da histérica (em 1928, Aragon e Breton, em La révolution surréaliste, comemoram o "Cinquantenaire de l'hystérie", afirmando a histeria como um "meio supremo de expressão"291), embora grande parte deles tivesse de Freud uma leitura de segunda mão, na medida em que as primeiras traduções do autor para o francês datam de 1921 e eram poucos os que podiam ler o texto no original.

Sabe-se ainda que o próprio Salvador Dalí inventou seu método paranóico-crítico inspirado pelas idéias de Freud e Lacan, autores por quem nunca escondeu sua admiração. Aliás, parece ter sido em Freud que Dalí foi buscar sua inspiração para suas gavetas, atravessando, como um traço pictográfico, os corpos de mulheres:

A única diferença entre a Grécia imortal e a época contemporânea é Freud, que descobriu que o corpo humano, que era puramente neoplatônico na época dos Gregos, está hoje cheio de gavetas secretas que só a psicanálise é capaz de abrir. ${ }^{292}$

Entretanto, não parece haver reciprocidade da parte de Freud e Lacan. A admiração dos psicanalistas pelos surrealistas é, no mínimo, ambivalente. É Lacan quem declara, mais de uma vez, não ter nada a ver com o surrealismo para o qual contribuiu "apenas marginalmente" e para alfinetar Breton, embora nos Escritos se encontrem duas referências de certa forma elogiosas ao autor. E é também Lacan quem dirá: "Imputam-me de bom grado um surrealismo que está longe de ser do meu agrado". ${ }^{293}$

\footnotetext{
${ }^{289}$ Jacqueline Chénieux-Gendron, O surrealismo, São Paulo, Martins Fontes, 1992, p. 28.

${ }^{290}$ Maria Gabriela Llansol, Um falcão no punho, Lisboa, Rolim, 1985, p. 47.

${ }^{291}$ J. Chénieux-Gendron, O surrealismo, op. cit., p. 27.

${ }^{292}$ Gilles Néret, Salvador Dalí - 1904-1989, Lisboa, Artes Gráficas, 1996, p. 44.

${ }^{293}$ German L. Garcia, "Jacques Lacan alude a Tristan Tzara”, in Françoise Giroud, et al., Lacan, você conhece? São Paulo, Cultura Editores Associados, 1993, p. 142, 145.
} 
Freud, que mereceu de Dalí vários esboços (Dalí teria chegado a oferecer-lhe um deles), demonstra recusar essa admiração dos surrealistas pela psicanálise, manifestando-se, ironicamente, como um "pai" assustado diante da "monstruosidade" que gerou. Diz ele, em carta a Stefan Zweig:

Até então, parece, eu estava tentado a me ocupar dos surrealistas que aparentemente me escolheram como santo padroeiro para os loucos integrais (digamos a 95\% como para o álcool absoluto). O jovem Espanhol, com seus olhos cândidos de fanático e sua inegável maestria técnica, me levou a reconsiderar minha opinião. Seria, com efeito, muito interessante estudar analiticamente a gênese de um quadro desse tipo. Do ponto de vista crítico, poder-se-ia dizer sempre que a noção de arte se recusa à toda extensão, uma vez que a relação quantitativa entre o material inconsciente e a elaboração pré-consciente não se mantém dentro dos limites determinados. De qualquer forma, tratase aí de sérios problemas psicológicos. ${ }^{294}$

A esse tipo de crítica, que Dalí receberá não só de Freud, mas de seus próprios colegas surrealistas, o jovem pintor espanhol responderia: "A única diferença entre um louco e eu é que eu não sou louco". Ou, dependendo do interlocutor: "A única diferença entre os surrealistas e eu, é que eu sou surrealista". ${ }^{295}$

Vê-se que estamos nos terrenos das perigosas semelhanças e das sutis diferenças. E aqui, nesse ponto em que aparentemente distinguem-se apenas posições teóricas e ideológicas, uma distinção mais sutil se permite entrever - aquela que demarca os territórios da psicanálise e da arte.

O que se pode perceber, numa leitura ligeira das obras artísticas e literárias do surrealismo, e sobretudo em suas formulações teóricas explicitadas especialmente pelos manifestos, é que os surrealistas, apossando-se antropofagicamente de alguns conceitos da psicanálise que eles mal puderam digerir, terminaram por construir a noção de um inconsciente romântico, de um desejo totalizador e totalizante e, sobretudo, a crença na possibilidade utópica de resgate do objeto perdido. ${ }^{296}$

Assim, a tendência à valorização do sonho e do desejo, por parte dos surrealistas, pode tanto desembocar num interesse nítido pela teoria psicanalítica quanto pelos fenômenos mediúnicos que invadiram o panorama da virada do século. Por isso, é possível a Benjamin Péret afirmar, em 1942, que, quando o surrealismo exalta o valor da magia, busca captar "o denominador comum a unir o feiticeiro, o poeta e o louco". ${ }^{297}$ Para esse dominador comum Freud se recusaria a contribuir, afastando, não sem certa ambivalência, a psicanálise desse trio maldito.

\section{III}

Entretant, para além do que declaram os manifestos e as teorias, para além do que proclamam seus mestres, surrealismo e psicanálise parecem basear-se em, pelo menos, um pressuposto comum, que me parece fundamental: aquele que garante à linguagem, tomada não exatamente em sua dimensão de representação, mas em sua dimensão de escritura, um dos lugares de sustentação de seus conceitos.

\footnotetext{
${ }^{294}$ Sigmund Freud apud Sarah Kofman, L'enfance de L'art, Paris, Payot, 1975, p. 141.

${ }^{295}$ Salvador Dali apud G. Néret, Salvador Dalí-1904-1989, op. cit., p. 7.

${ }^{296}$ A esse respeito, ver J. Chénieux-Gendron, $O$ surrealismo op. cit., p. 205-210; pontos de referência para situar o surrealismo no debate filosófico e psicanalítico.

${ }^{297}$ B. Péret, "Benjamin citado por J. Chénieux-Gendron", op. cit., p. 31.
} 
Às formulações de Freud acerca, por exemplo, do sonho, que é entendido então como uma escrita, como um rébus, corresponderia uma noção de arte que, valorizando o irracional, buscaria não exatamente interpretá-lo, mas grafá-lo, traçá-lo, escrevê-lo. Para os surrealistas, "não há pensamento fora das palavras" e as palavras, por sua vez, já se apresentam desde sempre escritas, aos olhos do leitor.

Esse movimento em direção à escrita - à escrita automática, mais propriamente corresponderia a uma tentativa de abolição de uma arte da mímese ou da representação:

Acima de tudo, esses textos [os textos surrealistas], na gratuidade de sua emergência e na ausência total de função representativa que é a sua, chegam entretanto a comunicar uma fantasia, visual ou não, que se torna comum ao 'scriptor' e ao leitor. Há aí um processo de abolição de tudo que distingue o objeto imaginário do objeto real, de tudo o que separa o "subjetivo" do "objetivo"... ${ }^{298}$

É, de fato, toda uma noção de representação que entra em crise com os movimentos de vanguarda da virada do século. Observe-se, em contrapartida, a valorização da materialidade da escrita efetuada por esses movimentos: os futuristas vão buscar as "palavras em liberdade", enquanto os dadaístas proporão técnicas de "saquinhos" de palavras aleatoriamente recortadas de um jornal. Os surrealistas, por sua vez, nitidamente inspirados pelo método freudiano da associação livre, buscarão na técnica da escrita automática uma tentativa de, abolindo a representação, escrever... o real.

A isso se deve, certamente, o privilégio da literatura dentre as modalidades da arte surrealista, a ponto de a revista veiculadora das idéias do movimento privilegiar, em seu nome, essa matéria: Littérature. Ao que Paul Valéry acrescentaria: "Littérature, souligné!", fazendo uma clara alusão ao final da "Art poétique" verlainiana, que dizia: "Et tout le reste est littérature". 299

Mesmo quando se trata das artes plásticas, o que se busca é uma escrita e não uma arte da representação. À escrita automática na literatura corresponderia uma arte automática, na pintura. E nessa, os desenhos terão mais o estatuto de traços, de rasuras, de lituras e letras, que propriamente de figurações.

O que a escritura de fato parece instaurar - tanto nas artes quanto na psicanálise - é um regime de legibilidade, em lugar do regime de interpretabilidade. $\mathrm{E}$ a legibilidade não implica, necessariamente, o deciframento completo, a leitura até o fim. A legibilidade, grande parte das vezes, esbarrará forçosamente no ponto de irredutibilidade da letra, implicando, antes, a escriptibilidade. Diante do que já não se dá a ler, talvez só seja possível escrever. ${ }^{300}$ Lembremo-nos de Lacan que, no posfácio do Seminário 11, dirá: "um escrito, a meu ver, é feito para não se ler". ${ }^{301}$

Segundo Ana Maria Netto Machado, em sua leitura do conceito de escrita na obra de Lacan, "essa é a astúcia fundamental que está no centro da invenção da escrita: a morte da imagem como representação da realidade e sua utilização exclusivamente pelo valor fonético ou de letra". 302

A proposta surrealista, centrada na escrita automática, talvez possa se resumir em sua tentativa romântica, irrealista até, de escrever o real. Lembremo-nos da definição do termo, no manifesto de 1924:

\footnotetext{
${ }^{298}$ J. Chénieux-Gendron, $O$ surrealismo, op. cit., p. 61-2.

${ }^{299}$ Idem, ibidem, p. 36.

${ }^{300}$ A esse respeito, ver Roland Barthes, $S / Z$, Rio de Janeiro, Nova Fronteira, 1992, p. 38.

301 Jacques Lacan, Seminário 11: os quatro conceitos fundamentais da psicanálise, 4 ed. Rio de Janeiro, Zahar, 1990, p. 263-6, posfácio.

302 Ana Maria Netto Machado, Presença e implicações da noção de escrita na obra de Jacques Lacan, Rio Grande do Sul, Unijuí, 1997, p. 140.
} 
SURREALISMO, n. m. Automatismo psíquico pelo qual alguém se propõe a exprimir seja verbalmente, seja por escrito, seja de qualquer outra maneira, o funcionamento real do pensamento. Ditado do pensamento, na ausência de todo controle exercido pela razão, fora de qualquer percepção estética ou moral. ${ }^{303}$

Ou, ainda, de alguns trechos do mesmo manifesto: "Creio na resolução futura desses dois estados, aparentemente tão contraditórios, quais sejam o sonho e a realidade, em uma espécie de realidade absoluta, de superrealidade se assim se pode chamar"; "O que há de admirável no fantástico é que não existe mais o fantástico: só há o real". 304

Esboça-se, aqui, pela ultrapassagem do conceito de realidade para o de suprarrealidade, um certo conceito de real. A tentativa dos surrealistas, em última instância, pode ser definida, a meu ver, como uma tentativa de escrever esse real. Essa é, aliás, a tentativa da arte e, nitidamente, a da literatura, em todos os tempos, como observa Roland Barthes:

O real não é representável, e é porque os homens querem constantemente representá-lo por palavras que há uma história da literatura. Que o real não seja representável - mas somente demonstrável - pode ser dito de vários modos: quer o definamos, com Lacan, como o impossível, o que não pode ser atingido e escapa ao discurso, quer se verifique, em termos topológicos, que não se pode fazer coincidir uma ordem pluridimensional (o real) e uma ordem unidimensional (a linguagem). Ora, é precisamente a essa impossibilidade topológica que a literatura não quer, nunca, renderse. Que não haja paralelismo entre o real e a linguagem, com isso os homens não se conformam, e é essa recusa, talvez tão velha quanto a própria linguagem, que produz, numa faina incessante, a literatura [...] Eu dizia há pouco, a respeito do saber, que a literatura é categoricamente realista, na medida em que ela sempre tem o real por objeto de desejo; e direi agora, sem me contradizer, porque emprego a palavra em sua acepção familiar, que ela é também obstinadamente: irrealista; ela acredita sensato o desejo do impossível. ${ }^{305}$

Poderíamos, então, pensar que algumas manifestações da arte buscam, ainda, a representação do real. Aí se alinham as diversas modalidades da arte da mimese, da arte realista propriamente dita. Outras, por sua vez, já não buscam a representação do real, mas sua escrita. Dentre elas, situa-se certamente o surrealismo. E nisso, apesar de sua suposta "inconsciência" (confundida, por muitos surrealistas, com o inconsciente, em Freud), o surrealismo aproxima-se da psicanálise.

\section{IV}

Marguerite Duras, em Escrever, surpreende-se e nos surpreende com uma curiosa observação de Lacan: "Ela não deve saber que escreve, nem aquilo que escreve. Porque ela se perderia. E isso seria uma catástrofe". ${ }^{306}$ A partir daí, a escritora desenvolve uma série de formulações acerca do perder-se na literatura. Dentre elas, a mais contundente, aquela que parece responder diretamente a Lacan: "A partir do momento em que se está perdido e que não se tem mais o que escrever, mais o que perder, aí é que se escreve". 307

\footnotetext{
303 André Breton, "Manifesto do Surrealismo", 1924, in Gilberto Mendonça Telles, Vanguarda européia e modernismo brasileiro, 6. ed., Rio de Janeiro, Vozes, 1976, p. 191.

${ }^{304}$ Idem, ibidem, p. 183.

${ }^{305}$ Roland Barthes, Aula, São Paulo, Cultrix, [s. d.], p. 22-3.

${ }^{306}$ Marguerite Duras, Escrever, Rio de Janeiro, Rocco, 1994, p. 19.

${ }^{307}$ Idem, ibidem, p. 21.
} 
Trata-se, evidentemente, de diferentes perder-se. Mas trata-se também dos sutis limites entre a psicanálise e a literatura. Porque a literatura e a arte precisam desse perder-se para se fazerem literatura e arte. É isso o que permite a Dalí declarar: "A única diferença entre um louco e eu é que eu não sou louco". Suficientemente lúcido, ou suficientemente louco para proferir tal declaração, Dalí não encontraria seus ecos entre os surrealistas que terminaram por expulsá-lo do movimento, levando-o a fazer pequenas alterações em sua formulação: "A única diferença entre os surrealistas e eu é que eu sou surrealista".

Declarando, publicamente, não sua loucura ou sua sanidade, mas a solidão essencial do artista - o único surrealista -, Dalí nos abandona, atordoados, com sua arte que dialoga, sempre enviesadamente, com a personagem Dalí, que ele mesmo criou.

Passeio pela exposição de Dalí: Dalí Monumental. De suas Vênus atravessadas por gavetas a seu Dom Quixote sentado, surpreende-me, por seu lirismo súbito, sua Gradiva, "aquela que avança". Aqui, também, mais um parentesco com Freud: a paixão por uma certa Gradiva. E é o personagem Dalí quem declara:

Ela [Gala] seria a minha Gradiva ("aquela que avança”), a minha vitória, a minha mulher. Mas para isso era preciso que ela me curasse. E ela curou-me, graças ao poder indomável e insondável do seu amor, cuja profundidade de pensamentos e capacidade prática ultrapassaram os mais ambiciosos métodos psicanalíticos

Poderia Freud dizer o mesmo? Teria sido ele também curado por suas Gradivas?

De qualquer maneira, à arte não interessa a cura, como essa deve interessar à psicanálise. À arte interessa, antes, a loucura, uma certa travessia da loucura que esbarra, sempre, no perder-se. O que não significa, necessariamente, que o artista e o louco se confundam. Nem sempre é assim, embora às vezes seja assim. $\mathrm{O}$ que não impede que a arte, surrealista ou não, possa, essa sim, à sua maneira, sempre declarar: "A única diferença entre o louco e eu é que eu não sou louca". 